\title{
Individuals at risk for Alzheimer's disease show differential patterns of ERP brain activation during odor identification
}

\author{
Charlie D Morgan ${ }^{1}$ and Claire Murphy ${ }^{1,2,3^{*}}$
}

\begin{abstract}
Background: Studies suggest that older adults at risk of developing Alzheimer's disease may show olfactory processing deficits before other signs of dementia appear.

Methods: We studied 60 healthy non-demented individuals, half of whom were positive for the genetic risk factor the Apolipoprotein E $\varepsilon 4$ allele, in three different age groups. Event-related potentials to visual and olfactory identification tasks were recorded and analyzed for latency and amplitude differences, and plotted via topographical maps.

Results: Varying patterns of brain activation were observed over the post-stimulus epoch for $\varepsilon 4$ - versus $\varepsilon 4+$ individuals on topographical maps. Individuals with the $\varepsilon 4$ allele demonstrated different ERP peak latencies during identification of olfactory but not visual stimuli. High correct ApoE classification rates were obtained utilizing the olfactory ERP.

Conclusions: Olfactory ERPs demonstrate functional decline in individuals at risk for Alzheimer's disease at much earlier ages than previously observed, suggesting the potential for pre-clinical detection of AD at very early stages.
\end{abstract}

Keywords: Alzheimer's disease, Apolipoprotein E, Olfactory event-related potentials, Age, Smell impairment, Olfaction

\begin{abstract}
Alzheimer's disease is a neurologic disorder accompanied by progressive memory loss, cognition loss and functional decline [1]. The cause or causes of AD are not yet known and definitive diagnosis can only be made via postmortem autopsy or, while living, a brain biopsy. The greatest risk factor for development of $\mathrm{AD}$ is advancing age. Genetic research has confirmed that the $\varepsilon 4$ allele of the apolipoprotein $\mathrm{E}$ (ApoE) gene is the strongest genetic risk factor for $\mathrm{AD}$ [2-5]. Inheritance of a single ApoE $\varepsilon 4$ variant increases a persons risk of developing $\mathrm{AD}$ by a factor of three in men and four in women, and having two copies of the $\varepsilon 4$ allele increases risk up to 15 -fold compared to persons without the $\varepsilon 4$ variant
\end{abstract}

\footnotetext{
* Correspondence: cmurphy@sciences.sdsu.edu

'Department of Psychology, San Diego State University, San Diego, CA 92120, USA

2University of California San Diego Medical Center, San Diego, CA 92120, USA

Full list of author information is available at the end of the article
}

[6,7]. Presence of the $\varepsilon 4$ allele increases the risk but does not guarantee future development of $\mathrm{AD}$ [8].

Studies have found olfactory dysfunction in AD including impairment in olfactory threshold sensitivity, odor identification, odor recognition memory, remote memory for odors, and odor fluency for review see [9]. Regions of the brain involved in the processing of olfactory information, such as the entorhinal cortex, prepiriform cortex, and the anterior olfactory nucleus show increased neuritic plaques and neurofibrillary tangles in $\mathrm{AD}$, as well as cell loss, granulovacuolar degeneration and tangles in the olfactory bulb [4,10-15]. The neuropathological changes associated with $\mathrm{AD}$ have been shown to affect the primary regions of the brain involved in olfaction but have less effect on other primary sensory areas [16]. Greater hippocampal atrophy has been reported in non-demented $\varepsilon 4+$ individuals compared to ع4- controls [17]. Studies of persons with the $\varepsilon 4$ allele have also demonstrated olfactory deficits in odor

\section{Biomed Central}


identification [18], odor detection [19] and odor memory [20], as well as odor recognition memory [21]. Odor identification appears to be particularly sensitive to cognitive changes associated with dementia. Correct classification rates of $100 \%$ have been obtained between persons at risk for $\mathrm{AD}$ from controls utilizing an odor identification test [22]. $\varepsilon 4+$ individuals demonstrate significantly poorer odor identification than $\varepsilon 4$ - nondemented older adults $[18,23]$. Odor identification abilities declined more rapidly in $\varepsilon 4+$ persons than $\varepsilon 4$ - persons over a four year time period while during the same time period there was no significant change in odor threshold, picture identification, or DRS scores [24]. Odor identification has been shown to be directly related to left hippocampal volume and to $\mathrm{AD}$ pathology in the brain $[25,26]$. Given that areas of the brain that process olfactory information are some of the earliest affected in $\mathrm{AD}$ and those at risk for $\mathrm{AD}$, olfactory changes may be some of the earliest signs of the disease in the preclinical phase.

Neuroimaging studies have suggested a functional recruitment hypothesis of age-related compensatory changes where those with $\mathrm{AD}$ and those at risk for $\mathrm{AD}$ utilize additional cognitive resources to bring memoryrelated performance to normal levels [27-33]. Persons with a positive family history $(\mathrm{FH})$ of $\mathrm{AD}$ and those with both $\mathrm{FH}$ and the $\varepsilon 4$ allele had greater activation predominantly in the bilateral posterior cingulate/precuneus, bilateral temporoparietal junction, and bilateral prefrontal cortex [34]. ApoE+ individuals produced greater brain activation in the bilateral fusiform gyri, right superior parietal cortex, left pyramis/uvula, left middle frontal gyrus, and medial frontal gyrus [29]. Similarly, participants diagnosed with Mild Cognitive Impairment or AD demonstrate greater activation in the frontal areas of the brain [35]. These studies suggest the potential for detection of $\mathrm{AD}$ and early preclinical stages using measures of brain response.

Brain activity can be measured from the surface of the scalp via the electroencephalogram and more specifically the event-related potential (ERP), a measure that is exquisitely sensitive to the timing of the brain's response. Olfactory event-related potentials (OERPs) recorded in relation to olfactory stimulation has demonstrated sensitivity to subtle changes in olfactory functioning associated with aging, disease, and ApoE status [36-45]. OERPs require odor stimulation via specially built olfactometers which control the exact timing of stimulus onset while avoiding simultaneous stimulation of other sensory modalities such as stimulation of the trigeminal system [39,46-49]. These olfactometers also warm and humidify the air stream in order to prevent somatosensory cues. Reaction times to odors vary based on the stimulus and subject characteristics but range from 800 -
$900 \mathrm{~ms}$ [50]. Neuronal recovery time of the olfactory system is much longer than other sensory systems $[38,51,52]$. Auditory and visual stimuli can be presented every 2-3 seconds in ERP research without significant adaptation [53-55] while in the olfactory system interstimulus intervals of 30-45 seconds are required. This slower neuronal recovery is partially due to olfactory receptor cells that rapidly adapt and slowly recover [56] and partially due to habituation [52]. Given longer interstimulus intervals in olfactory stimulation, fewer trials are presented than in other systems in order to reduce potential subject fatigue and loss of vigilance. A narrower filter is also applied when processing the ERP data to compensate for the smaller number of trials.

The early components of the OERP, the N1, P2, and $\mathrm{N} 2$ are considered exogenous sensory components that have been associated with odor threshold and odor identification $[38,49,57]$. The P3 component in general represents endogenous processing of a stimulus, reflecting both stimulus classification speed and the ability to attend to and evaluate a stimulus [58,59]. OERP P3 latency correlates with neuropsychological tests that measure memory and cognitive processing speed [60]. Several studies have demonstrated increased OERP peak latencies associated with aging $[36,38,39,41,60]$. Older males produced significantly smaller OERP peak amplitudes than older females when utilizing relatively short interstimulus intervals, suggesting greater olfactory impairments in males [38]. Studies of the OERP have further documented olfactory deficits in AD [61], specifically longer P2 and P3 latencies in AD patients compared to controls. These latency measures also correlate significantly with dementia status as measured by the Dementia Rating Scale (DRS). Importantly, studies utilizing the OERP with persons at risk for $\mathrm{AD}$, due to the ApoE $\varepsilon 4$ allele, have also demonstrated differences. $\varepsilon 4+$ nondemented older adults produced significantly longer OERP latencies than age-matched $\varepsilon 4$ - individuals [62]. Additionally, high sensitivity and specificity was obtained in classifying $\varepsilon 4+$ and $\varepsilon 4$ - individuals based on OERP latency alone. Utilizing a cross-modal odor recognition memory task differential brain activity was observed between ApoE groups, such that $\varepsilon 4$ - participants differed from $\varepsilon 4+$ participants in activation of the frontal electrode sites, supporting the compensatory hypothesis [63].

This study examines OERPs in an odor identification task compared to a picture identification task in three separate age groups and in persons positive and negative for the $\varepsilon 4$ allele. We hypothesized that $\varepsilon 4+$ individuals would demonstrate differing topographical patterns of brain activation compared to $\varepsilon 4$ - individuals as measured by the ERP. As in previous studies we also hypothesized that $\varepsilon 4+$ older adults would produce longer OERP peak latencies than $\varepsilon 4$ - participants and that this 
difference would be greater than differences measured with an odor threshold test and a traditional odor identification test (San Diego Odor Identification Test).

\section{Methods and materials Participants}

Participants were 60 adults divided into three age groups, Young Adults $(10 \mathrm{M}, 10 \mathrm{~F}$, Mean age $=22.8$ years $)$, Middle Age Adults $(10 \mathrm{M}, 10 \mathrm{~F}$, Mean Age $=50.5)$, and Older Adults $(10 \mathrm{M}, 10 \mathrm{~F}$, Mean age $=70.7)$. Half of each group were positive for the $\varepsilon 4$ allele. Table 1 presents demographic variables by age and ApoE groups. Participants were recruited from the general community, from San Diego State University, and from an ongoing subject pool at the Lifespan Human Senses Laboratory. The research was approved by IRBs at San Diego State University and the University of California, San Diego and subjects gave informed consent. All participants were screened for odor sensitivity via odor threshold test and odor identification test and any participants with threshold scores lower than 4 , or odor identification scores less than 3 , were excluded from the study $[22,64,65]$. Participants were screened for cognitive impairment using the Dementia Rating Scale, and any participants scoring less than 133 were excluded from the study [66]. Genetic DNA was obtained from each subject using buccal swab of cheek cells and analyzed for the APOE genotype at an offsite laboratory as described in [67]. Data from 40 of these participants have previously been published [68].

\section{Procedure}

\section{San Diego Odor Identification Test (SDOIT)}

The San Diego Odor Identification Test $[22,57,69]$ consists of 8 common household odors (e.g. chocolate, coffee) presented in opaque jars. A set of 20 line drawings of the 8 odors and 14 distractors, presented in an array, were placed in front of each participant. Participants smelled the odors birhinically in random order and chose the odor from the array of drawings. Verbalizing the name of the odor or pointing to the picture of the odor were both acceptable ways of responding. Total number correct of the 6 most commonly identified odors was used for analysis.

\section{ERP stimulus presentation}

Olfactory stimulation was performed via computer controlled olfactometer incorporating designs of previous olfactometers [39,46-49]. Odors were presented utilizing a single stimulus paradigm for $200 \mathrm{msec}$ and an interstimulus interval (ISI) of $30 \mathrm{sec}$. Participants employed Velopharyngeal closure to restrict breathing to the mouth and thereby maintain a constant odorant flow rate $[46,48,70]$. Fourteen separate odors (banana, rose, cinnamon, peanut butter, baby powder, mustard, chocolate, pine, lemon, orange, vanilla, coffee, leather, wintergreen) were presented twice each in pseudo-randomized order. Six of these odors were chosen in order to replicate the most identifiable odors from the San Diego Odor Identification Test $[22,57,69]$. All odorants were undiluted and two drops of each odorant were placed into the olfactometer before each subject session. After each odor presentation the participants were asked to identify the odor via button press from a list of four written options presented on the computer screen in front of them and their responses were recorded electronically.

In a separate experimental session on the same testing day, 28 visual line drawings of objects from the Boston Naming Test [71] were presented on a computer screen in front of the subject. Duration of each stimulus was $200 \mathrm{msec}$ with $30 \mathrm{sec}$ ISIs. As in the olfactory identification task the subjects were asked to identify each picture via button press from a list of four written options on the computer screen. Both olfactory and visual stimuli were presented via Compumedics STIM ${ }^{2}$ software. Order of experimental presentation, olfactory or visual, was randomized across subjects so that some subjects received the visual experiment first, and some the olfactory experiment first.

\section{ERP recording}

Olfactory and visual ERPs were obtained via Compume$\operatorname{dics}^{\text {Tx }}$ 64-electode AG/AG/CL sintered Quick-Cap and

Table 1 Means and Standard Deviations for demographic, behavioral and performance data for each age and ApoE group

\begin{tabular}{|c|c|c|c|c|c|c|}
\hline & & poE Negati & & & poE Positiv & \\
\hline & Young & Middle & Older & Young & Middle & Older \\
\hline Age (years) & $22.6(2.0)$ & $50.7(1.7)$ & $71.2(3.6)$ & $23.1(2.3)$ & $50.2(4.5)$ & $70.2(2.9)$ \\
\hline Education (years) & $14.7(2.8)$ & $14.9(2.5)$ & $16.1(2.3)$ & $14.9(1.7)$ & $15.2(2.3)$ & $14.8(3.2)$ \\
\hline Dementia Rating Scale Score (144 max) & $142.4(2.0)$ & $139.8(4.8)$ & $140.3(2.9)$ & $140.3(5.0)$ & $140.8(4.1)$ & $141.5(2.1)$ \\
\hline Odor Threshold (dilution steps, 9 max) & $7.4(1.3)$ & $6.7(1.1)$ & $6.3(1.4)$ & $7.3(1.5)$ & $6.8(1.9)$ & $4.4(1.3)$ \\
\hline Odor Identification Test (6 max) & $5.9(0.3)$ & $4.9(1.2)$ & $5.0(1.3)$ & $5.6(0.5)$ & $4.8(1.4)$ & $4.3(1.2)$ \\
\hline OERP \# Correctly Identified (28 max) & $20.1(4.3)$ & $19.9(6.1)$ & $18.7(4.2)$ & $18.3(3.9)$ & $15.5(3.7)$ & $17.6(4.0)$ \\
\hline VERP \# Correctly Identified (28 max) & $21.2(7.8)$ & $26.0(2.1)$ & $25.7(2.8)$ & $22.7(4.0)$ & $22.1(6.5)$ & $26.3(2.2)$ \\
\hline
\end{tabular}


Quick-Cell system, amplified via Synamps 2 amplifiers, and recorded on computer hard disk via the Neuroscan software package. Electrode impedances were kept below $10 \mathrm{k} \Omega$. At the time of recording the EEG data were digitized at $500 \mathrm{~Hz}$ through a 0.1 to $30 \mathrm{~Hz}$ bandpass filter. Offline, the data were further filtered through a 0.1 to $6 \mathrm{~Hz}$ bandpass filter. Artifactual eyeblink activity was recorded and corrected offline via the Neuroscan software utilizing the Occular Artifact Reduction method within the software. ERP trials that included other types of artifactual activity were excluded using both automated exclusion (e.g. excluding all trials with voltage ranges larger than $50 \mu \mathrm{V}$ ) and by visually inspecting each trial prior to averaging. Ongoing EEG activity was recorded throughout the experiment and then trials epoched offline to $500 \mathrm{msec}$ pre-stimulus and $1500 \mathrm{msec}$ post-stimulus. Baseline corrected trials were then averaged. Peak amplitudes were measured from the prestimulus baseline to maximum peak amplitude. Latency windows from previous OERP studies [38,39] were used as guidelines to identify peak components. Peaks were picked blindly as to age, gender, and APOE status in order to avoid experimenter bias.

\section{Results}

\section{Demographics and screening measures}

Table 1 summarizes demographic and screening measures. Within each age group there were no significant differences in mean participant age between ApoE+ and ApoE- participants ( $p$ >.05). Dementia Rating Scale scores did not differ significantly between ApoE groups or age groups $(\mathrm{p}>.05)$ and all participants' DRS scores were in the range of normal cognitive functioning. Analysis of odor threshold test performance revealed that all participants scored in the normal range of olfactory functioning. While all participants were normosmic, the older participant group exhibited poorer olfactory threshold scores than the middle and young age groups $\left(\mathrm{F}(2,57)=8.93, \mathrm{p}<.001, \eta^{2}=.24\right)$, with no interaction of ApoE status.

\section{Odor and picture identification}

Table 1 shows identification scores by age and ApoE groups. Analysis of the San Diego Odor Identification Test revealed no significant main effects or interaction effects involving ApoE status ( $p$ >.05). It did demonstrate a significant main effect of age $(F(2,57)=6.04$, $\mathrm{p}<.01, \eta^{2}=.18$ ) with young participants correctly identifying more odors than both the middle and older age groups $(\mathrm{p}<.05)$.

Analysis of correctly identified number of odors from the Odor Identification ERP task revealed a main effect of ApoE status collapsed across age groups $(\mathrm{F}(1,54)=$ 4.54, $\left.\mathrm{p}<.05) \quad \eta^{2}=.08\right)$, such that $\varepsilon 4$ - participants correctly identified more odors than $\varepsilon 4+$ participants. The number of correctly identified odors did not differ significantly by ApoE status when each age group was analyzed separately, (suggesting that this effect is small when the screening measures are applied). Analysis of correctly identified pictures in the Picture Identification ERP task revealed a significant main effect of age group $\left(\mathrm{F}(2,54)=3.60, \mathrm{p}<.05, \eta^{2}=.12\right)$, such that older participants correctly identified more pictures than young participants $(p<.05)$. The effect of ApoE status was not significant for Picture Identification.

\section{Topographical displays of ERP activity}

Figure 1 illustrates topographical distributions of OERP amplitudes in $\mu \mathrm{V}$ over the post-stimulus time interval from $700 \mathrm{~ms}$ through $1300 \mathrm{~ms}$ by age and ApoE groups. For each of 19 electrodes (FP1, FP2, F7, F3, F2, F4, F8, T7, C3, CZ, C4, T8, P7, P3, P2, P4, P8, O1, O2) amplitudes were averaged over the $100 \mathrm{~ms}$ time intervals (e.g. 700-800 ms) and input into graphing software in order to visually display brain activity across the scalp for each age and APOE group. Given no significant ApoE effects in the visual modality only olfactory ERP topographies are shown. In the young group the OERP topographical maps show greater brain activation in the $\varepsilon 4+$ participants compared to $\varepsilon 4$ - participants, over the left hemisphere electrodes, and particularly over parietal electrodes, that decreases after 1100 ms. Middle age $\varepsilon 4+$ and $\varepsilon 4$ - individuals demonstrated similar topographies, however $\varepsilon 4+$ participants showed somewhat more activity over the right hemisphere electrodes compared to left, in the 900-1100 ms range, whereas $\varepsilon 4$ - participants showed more central electrode activity across the recording epoch. The greatest differences can be observed in the older groups where $\varepsilon 4$ - participants showed an increase in activation over left and central electrode sites between 900-1100 ms, and $\varepsilon 4+$ participants showed relatively less overall activation during that time period, but increasing activation over right frontal electrodes between 1000-1200 ms. Overall the topographical maps clearly illustrate that brain activity related to olfactory processing differs not only by age, but more importantly by ApoE status, and the activity differentially changes over the post-stimulus time period.

\section{Event Related Potentials (ERPs)}

Repeated measures multivariate analyses of variance (MANOVAs) were performed for each ERP component (N1, P2, N2, P3) and olfactory and visual modalities were analyzed separately for each peak amplitude and latency. Greenhouse-Geisser corrections were applied to all MANOVAs. Significant main effects and interactions were further analyzed with post hoc Newman Keuls 


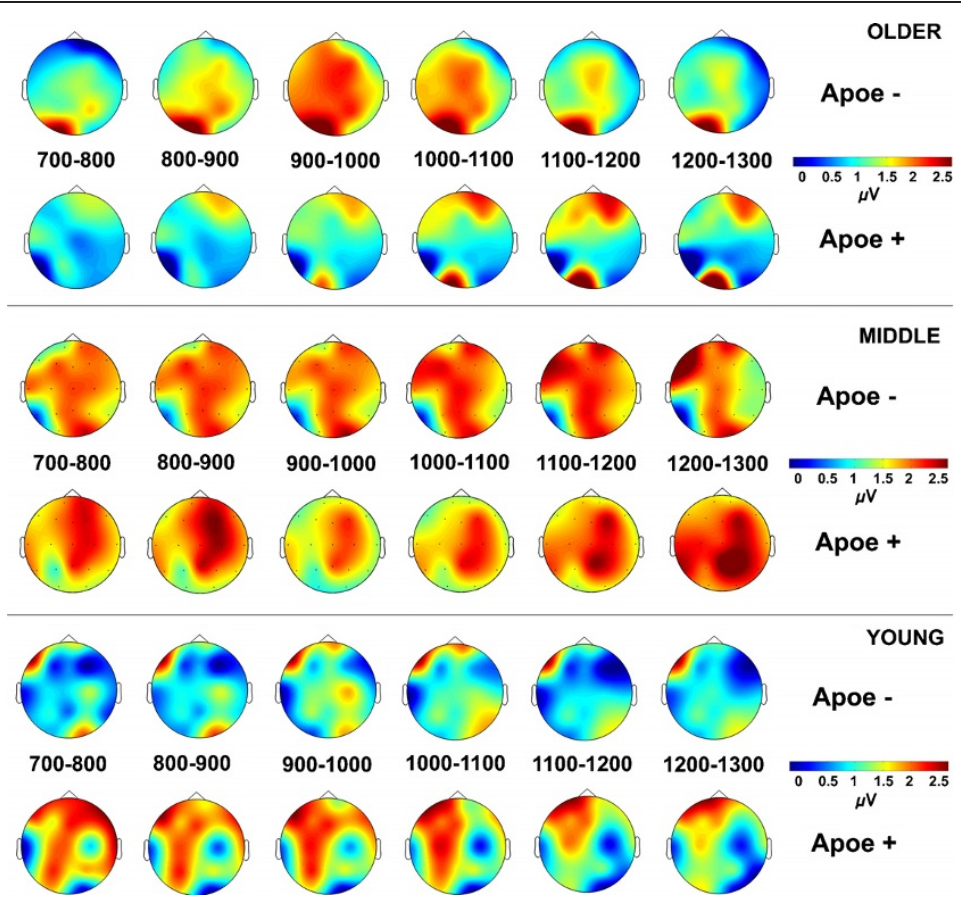

Figure 1 Topographical representation of OERP amplitudes in $\mu \mathrm{V}$ across 19 electrode sites by age and ApoE groups for 700-1300 ms post-stimulus time intervals.

Multiple Range Tests (alpha 0.05). Significant visual and olfactory ERP effects are summarized in Table 2.

\section{Picture identification ERPs}

Visual N1, P2, and N2 amplitudes demonstrated no significant main or interaction effects $(\mathrm{p}>.05)$. Visual P3 amplitude demonstrated a significant main effect for electrode site $\left(\mathrm{F}(2,108)=4.28, \mathrm{p}<.05, \eta^{2}=.07\right)$ such that the $\mathrm{Cz}$ and $\mathrm{Pz}$ electrode sites produced larger P3 amplitudes than the Fz site.

Figure 2 illustrates visual ERP peak latencies. Visual $\mathrm{N} 1$ and P2 latencies did not demonstrate significant main or interaction effects $(p>05)$. Visual N2 latency demonstrated a significant main effect of electrode site $\left(\mathrm{F}(2,108)=3.50, \mathrm{p}<.05, \eta^{2}=.06\right)$ with the Pz electrode site producing shorter N2 latencies than the Fz electrode site. Visual P3 latency also revealed a significant main effect of electrode site $\left(F(2,108)=8.78, p<.01, \eta^{2}=.14\right)$ with the $\mathrm{Cz}$ and Pz electrode sites recording significantly longer latencies than the Fz site $(\mathrm{p}<.01)$. Visual P3 latency also showed a significant main effect of age group $\left(\mathrm{F}(2,54)=4.94, \mathrm{p}<.05, \eta^{2}=.15\right)$ with older adults producing significantly longer visual P3 latencies than young adults $(\mathrm{p}<.01)$.

\section{Odor identification ERPs}

Olfactory N1, P2, and P3 amplitudes demonstrated no significant main or interaction effects $(p>.05)$. Olfactory
N2 amplitude demonstrated a significant main effect of age $\left(F(2,54)=3.62, \mathrm{p}<.05, \eta^{2}=.12\right)$ with older age participants producing significantly more negative N2 amplitudes than middle age participants.

Figure 2 illustrates olfactory ERP peak latencies. Olfactory N1, P2, N2, and P3 latencies demonstrated significant interaction effects of Age $\mathrm{x}$ ApoE status $\left(\mathrm{N} 1: \mathrm{F}(2,54)=4.73, \mathrm{p}<.05, \eta^{2}=.15 ; \mathrm{P} 2: \mathrm{F}(2,54)=9.34\right.$, $\mathrm{p}<.001, \eta^{2}=.26 ; \mathrm{N} 2: \mathrm{F}(2,54)=8.18, \mathrm{p}<.01, \eta^{2}=.23$; P3: $\left.F(2,54)=14.11, p<.001, \eta^{2}=.34\right)$. Post hoc analyses of the interaction effects revealed that in the young group those negative for the $\varepsilon 4$ allele produced significantly longer N2 $\left(\eta^{2}=.26\right)$, and P3 $\left(\eta^{2}=.29\right)$, latencies. In the middle age group those positive for the $\varepsilon 4$ allele produced significantly longer $\mathrm{N} 1 \quad\left(\eta^{2}=.31\right)$, and P2 $\left(\eta^{2}=.31\right)$ latencies. In the older group those positive for the $\varepsilon 4$ allele produced significantly longer latencies for all components $\mathrm{N} 1\left(\eta^{2}=.50\right), \mathrm{P} 2\left(\eta^{2}=.52\right), \mathrm{N} 2\left(\eta^{2}=.35\right)$, and P3 $\left(\eta^{2}=.59\right)$. For $\mathrm{N} 1$ and P3 latencies, in both ApoE groups, older participants produced significantly longer latencies than middle age participants and middle age participants produced longer latencies than young participants. For P2 and N2 latencies in $\varepsilon 4+$ participants, this same pattern was observed, however in ع4- participants young adults did not differ significantly from middle age participants, but both young and middle age participants produced shorter latencies than older participants. 
Table 2 Summary of analyses performed and effect sizes for peak component amplitudes and latencies

\begin{tabular}{|c|c|c|c|c|c|c|c|c|}
\hline \multirow[t]{2}{*}{ Peak measures } & \multicolumn{4}{|c|}{ Amplitude } & \multicolumn{4}{|c|}{ Latency } \\
\hline & N1 & P2 & N2 & P3 & N1 & P2 & N2 & P3 \\
\hline \multicolumn{9}{|l|}{ Picture ID ERPS } \\
\hline Age (A) & - & - & - & - & - & - & - & $*(\eta=.15)$ \\
\hline ApoE Status (S) & - & - & - & - & - & - & - & - \\
\hline Electrode (E) & - & - & - & $*(\eta=.07)$ & - & - & $*(\eta=.06)$ & $*(\eta=.14)$ \\
\hline$A \times S$ & - & - & - & - & - & - & - & - \\
\hline$A \times E$ & - & - & - & - & - & - & - & - \\
\hline$S \times E$ & - & - & - & - & - & - & - & - \\
\hline$A \times S \times E$ & - & - & - & - & - & - & - & - \\
\hline \multicolumn{9}{|l|}{ Odor ID ERPs } \\
\hline Age $(A)$ & - & - & $*(\eta=.12)$ & - & $* * *(\eta=.70)$ & $* * *(\eta=.68)$ & $* * *(\eta=.64)$ & $* * *(\eta=.76)$ \\
\hline ApoE Status (S) & - & - & - & - & $* * *(\eta=.27)$ & $* * *(\eta=.22)$ & - & - \\
\hline Electrode (E) & - & - & - & - & - & - & - & - \\
\hline$A \times S$ & - & - & - & - & $*(\eta=.15)$ & $* * *(\eta=.26)$ & $* *(n=.23)$ & $* * *(\eta=.34)$ \\
\hline$A \times E$ & - & - & - & - & - & - & - & - \\
\hline$S \times E$ & - & - & - & - & - & - & - & - \\
\hline$A \times S \times E$ & - & - & - & - & - & - & - & - \\
\hline
\end{tabular}

Correlational analyses were performed between the ERP odor ID performance and average $(\mathrm{Fz}, \mathrm{Cz}, \mathrm{Pz})$ peak latencies (N1, P2, N2, P3). When all ages and ApoE groups were combined together odor ID performance marginally correlated with $\mathrm{N} 1$ latency $(\mathrm{r}=-.28, \mathrm{p}<.05)$. Correlational analyses were also performed for each age $\mathrm{x}$ ApoE group separately. The only significant correlation between odor ID performance and latency was for $\mathrm{N} 1$ latency in the older Apoe+ group $(\mathrm{r}=-.77, \mathrm{p}<.01)$.

\section{Logistic regression analyses of OERP variables}

In order to better understand the predictive value of the ERP in differentiating $\varepsilon 4$ - and $\varepsilon 4+$ participants, stepwise logistic regression analysis was performed on olfactory N1, P2, N2, P3 amplitude and latency averaged over Fz, $\mathrm{Cz}$, and Pz. Visual ERP variables were not included in logistic regression analysis because no significant ApoE effects were present. A logistic regression is a type of regression analysis used to predict the outcome of a binary dependent variable (e.g. Apoe+ vs Apoe-) based on one or more predictor variables (e.g. ERP amplitude and latency). The logistic regression analysis outputs predictive classification results including overall correct classification (total percentage of correctly classified individuals), as well as sensitivity (e.g. APOE+ correctly classified as $\mathrm{APOE}+$ ) and specificity (e.g. APOE- correctly classified as APOE-). In the olfactory modality analysis of all age groups combined revealed that olfactory N1 latency was the most significant single predictor in discriminating between $\varepsilon 4+$ participants and $\varepsilon 4$ - participants $\left(x^{2}=6.07\right.$, $\mathrm{p}<.05)$ resulting in an overall correct classification rate of $70.0 \%$ (Sensitivity $=66.7 \%$, Specificity $=73.3 \%$ ). When $\mathrm{P} 3$ latency was also added to N1 amplitude in the model $\left(x^{2}=8.06, p<.01\right)$ overall correct classification rate increased to $76.7 \%$ (Sensitivity $=80 \%$, Specificity $=$ 73.3\%). Logistic regressions were also performed for each age group separately in order to better understand the effects of ApoE status within each age group. In the young participant group N2 amplitude was the most significant predictor $\left(\mathrm{X}^{2}=7.79, \mathrm{p}<.01\right)$ resulting in an overall classification rate of $65.0 \%$ (Sensitivity $=70.0 \%$, Specificity $=60.0 \%$ ). In the middle age group P2 latency was the most significant single predictor $\left(X^{2}=6.86\right.$, $\mathrm{p}<.01)$ resulting in an overall classification rate of $80.0 \%$ (Sensitivity $=80.0 \%$, Specificity $=80.0 \%)$. When P3 amplitude and P3 latency were also added to the equation with P2 latency $\left(x^{2}=20.09, p<.001\right)$, the overall classification rate for middle age participants increased to $90.0 \%$ (Sensitivity $=90.0 \%$, Specificity $=90.0 \%$ ). In the older age group P3 latency was the most significant single predictor $\left(\chi^{2}=16.37, \mathrm{p}<.001\right)$ resulting in an overall classification rate of $90.0 \%$ (Sensitivity $=90.0 \%$, Specificity $=90.0 \%)$. When $\mathrm{N} 1$ latency was also added to the equation with P3 latency $\left(X^{2}=27.73, p<.001\right)$, overall classification rate for older participants increased to $100.0 \%$ (Sensitivity $=100.0 \%$, Specificity $=100.0 \%$ ). 


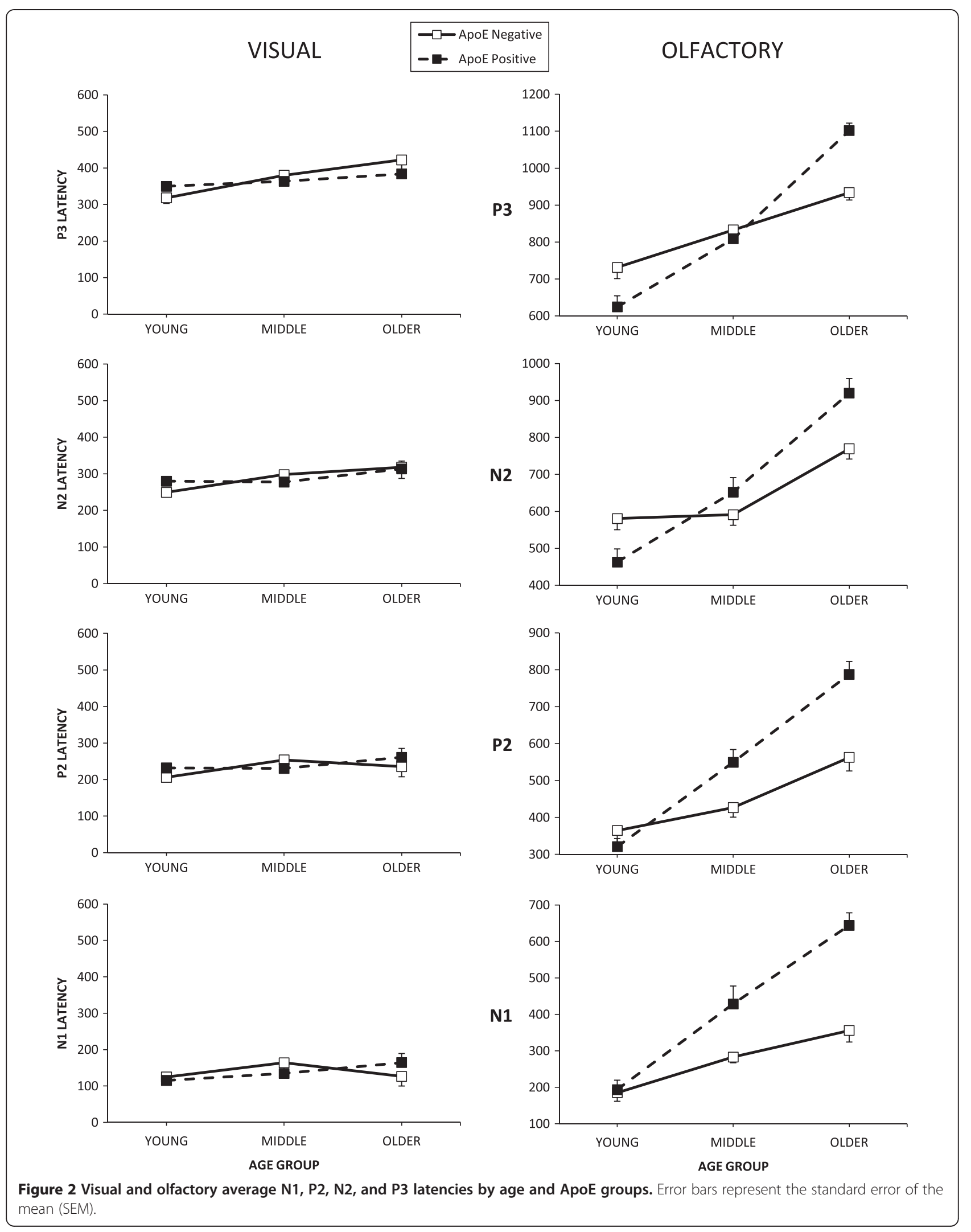




\section{Discussion}

This study demonstrated (1) robust odor identification ERP differences based on ApoE status and interactions with age; (2) high correct ApoE classification rates utilizing the OERP that were different for each age group.

A few previous studies have demonstrated ERP impairments in persons with a positive family history of $A D$, in those diagnosed with early $\mathrm{AD}$, and in individuals with mild cognitive impairment (MCI). MCI is commonly defined as subtle but measurable memory impairment without any other symptoms of dementia. Green et al. [72] demonstrated auditory ERP P3 latency increases in pre-clinical groups of persons with a family history of $\mathrm{AD}$ and in those with a family history plus $\varepsilon 4+$ status. They did not indicate, however, how many of the participants demonstrated this latency difference, or how well this measure correctly classified participants into $\varepsilon 4+$ or ع4- groups. Olichney et al. [73] studied participants diagnosed with MCI utilizing an N400/P600 semantic congruency task and then tracked those participants over time. Participants with abnormal N400 or P600 effects had an 87 to $88 \%$ likelihood of progression to dementia within 3 years. They suggest that these N400 abnormalities in MCI may reflect subtle dysfunction of semantic memory processes. Utilizing this method, classification of participants into diagnostic groups was high in sensitivity in $\mathrm{MCI}$ who converted to $\mathrm{AD}$ (81-94\%) less so when applied to all participants (58 to 65\%). Chapman et al. [74] used a visual number-letter memory task to study ERPs in participants diagnosed as being in the early stages of $\mathrm{AD}$. Their results suggest that $\mathrm{AD}$ deficits may include problems with storage in short-term memory, and that difficulties may lie in the cognitive processing of stimuli that are relevant to the task in which the participant is engaged. Using this method the authors were able to correctly classify $92 \%$ of participants into $\mathrm{AD}$ or control groups. While these studies are extremely helpful in understanding cognitive changes associated with early stages of dementia, even at the MCI stage, they also raise the possibility of early diagnosis at even earlier, pre-MCI, pre-clinical, stages of $\mathrm{AD}$. A measure that would aid diagnosis of AD many years before any manifestation of other signs or symptoms would be ideal, especially once an effective medication for halting or altering the dementing process is developed.

Illustrated on the ERP topographical maps, the current study demonstrated differing patterns of brain activity recorded over the scalp, depending on ApoE status. fMRI studies on activation have reported mixed results, with some showing increased activation in $\varepsilon 4$ carriers $[30,75]$, and others demonstrating reduced activation in $\varepsilon 4$ carriers [76]. The current study demonstrates that patterns of brain activation differ not only by ApoE status, but across age groups, and that the pattern of activation changes across time over the post-stimulus interval of cognitive processing. This suggests that processing of olfactory stimuli is differentially affected by presence or absence of the $\varepsilon 4$ allele. Additionally these effects change over the lifespan, such that individuals in different decades of life, even young adults, show varying patterns of brain activation.

In the present study, it is important to note that in order to better understand the effects of the ApoE risk factor at points before memory problems are present, participants with dementia, early dementia, or mild cognitive impairment, as well as those with anosmia or severe hyposmia, were screened out of the study. Given this rigorous screening process, it is not surprising that no significant ApoE effects were found for the visual picture identification task. Very robust effects of ApoE status were demonstrated for the odor identification ERP task, as well as significant age by ApoE interaction effects. This occurred despite no difference in performance on the Dementia Ratings Scale, odor threshold testing, or the SDOIT by ApoE status. The present study strongly suggests that combining olfactory processing with cognitive processing [odor identification] may be sensitive enough to differentiate very early those with a high likelihood from those with a low likelihood of developing $\mathrm{AD}$, even as early as middle age. This together suggests the ability to identify odors and the speed of odor identification is slowed in the presence of the $\varepsilon 4$ allele. Picture identification remained intact in ApoE+ participants, both for number of pictures correctly identified and speed with which the pictures were cognitively processed.

Of further note, the present study demonstrated good ApoE classification rates of $80 \%$ in the middle age group, with $\varepsilon 4+$ participants producing significantly longer N1 and P2 latencies than $\varepsilon 4$ - participants. It suggests that ApoE-related olfactory functional decline is taking place at much earlier ages than previously observed, further suggesting that early, pre-clinical, diagnosis of $\mathrm{AD}$ may be a real possibility. Consistent with previous OERP studies [62,63], older $\varepsilon 4+$ participants produced significantly longer OERP peak latencies. In this group 100\% classification rates were obtained suggesting a clear delineation in performance between $\varepsilon 4+$ and $\varepsilon 4$ - participants once they reach ages above 65 years old.

Further research needs to examine the utility of various measures and tasks in the study of pre-clinical AD, in order to capture the pre-dementing processes at the earliest possible stages, and improve diagnostic ability. Olfactory tasks involving cognitive processing, such as the OERP, appear to be very promising in this regard.

\section{Competing interest}

The authors report no biomedical financial interests or potential conflicts of interest. 


\section{Authors' contributions}

CDM and CM designed the study and advised the research assistants through data collection and analysis, and interpreted the data. CDM constructed the olfactometer. CDM and CM wrote and approved the final version of the manuscript.

\section{Acknowledgments}

Supported by NIH Grant DC002064 to Claire Murphy. The authors would like to thank the late Dr. Leon Thal and the UCSD ADRC (P50AG005131-28) for genotyping, Dr. John Polich, Krystin Corby, Joel Kowalewski, Jessica Bartholow, and Roberto Zamora for research assistance.

\section{Author details}

'Department of Psychology, San Diego State University, San Diego, CA 92120, USA. ²University of California San Diego Medical Center, San Diego, CA 92120, USA. ${ }^{3}$ SDSU/UCSD Joint Doctoral Program, 6363 Alvarado Ct. Suite 101, San Diego, CA 92120-4913, USA

Received: 22 January 2012 Accepted: 15 June 2012

Published: 31 July 2012

\section{References}

1. American Psychiatric Association: Diagnostic and statistical manual of mental disorders, Revised 4th ed. Washington, DC: American Psychiatric Press; 2000.

2. Blacker D: The genetics of Alzheimer's disease: progress, possibilities, and pitfalls. Harv Rev Psychiatry 1997, 5(4):234-237.

3. Combarros O, Alvarez-Arcaya A, Sanchez-Guerra M, Infante J, Berciano J: Candidate gene association studies in sporadic Alzheimer's disease. Dement Geriatr Cogn Disord 2002, 14(1):41-54.

4. Corder EH, Saunders AM, Strittmatter WJ, Schmechel DE, Gaskell PC, Small GW, Roses AD, Haines JL, Pericakvance MA: Gene dose of apolipoprotein E type 4 allele and the risk of Alzheimer's disease in late onset families. Science 1993, 261(5123):921-923.

5. Teter B, Raber J, Nathan B, Crutcher KA: The presence of apoE4, not the absence of apoE3, contributes to AD pathology. J Alzheimers Dis 2002, 4:155-163.

6. Bertram L, Tanzi RE: The genetic epidemiology of neurodegenerative disease. J Clin Invest 2005, 115(6):1449-1457.

7. Farrer LA, Cupples LA, Haines JL, Hyman B, Kukull WA, Mayeux R, Myers RH, Pericakvance MA, Risch N, vanDuijn CM: Effects of age, sex, and ethnicity on the association between apolipoprotein E genotype and Alzheimer disease - A meta-analysis. JAMA 1997, 278(16):1349-1356.

8. Burke $W$, Pinsky LE, Press NA: Categorizing genetic tests to identify their ethical, legal, and social implications. Am J Med Genet 2001, 106(3):233-240.

9. Murphy C: Loss of olfactory function in dementing disease. Physiol Behav 1999, 66(2):177-182.

10. Averback P: 2 new lesions in Alzheimers-disease. Lancet 1983 2(8360):1203.

11. Braak H, Braak E: Frequency of stages of Alzheimer-related lesions in different age categories. Neurobiol Aging 1997, 18:351-357.

12. Christen-Zaech S, Kraftsik R, Pillevuit O, Kiraly M, Martins R, Khalili K, Miklossy J: Early olfactory involvement in Alzheimer's disease. Can J Neurol Sci 2003, 30(1):20-25

13. Esiri MM, Wilcock GK: The Olfactory bulbs in Alzheimers-disease. J Neurol Neurosurg Psychiatry 1984, 47(1):56-60.

14. Ohm TG, Braak H: Olfactory-Bulb Changes in Alzheimers-Disease. Acta Neuropathol 1987, 73(4):365-369.

15. Reyes PF, Golden GT, Fariello RG, Fagel L, Zalewska M: Olfactory pathways in Alzheimer's disease (AD): Neuropathological studies [abstract]. Society for Neuroscience 1985, 11:168.

16. Van Hoesen GW, Solodkin A: Cellular and systems neuroanatomical changes in Alzheimer's disease. In: Calcium hypothesis of aging and dementia. Disterhoft JF, Khachaturian ZS (eds). Proc NY Acad Sci (USA) 1994, 747:12-35

17. den Heijer T, Oudkerk M, Launer LJ, Van Duijn CM, Hofman A, Breteler MM: Hippocampal, amygdalar, and global brain atrophy in different apolipoprotein E genotypes. Neurology 2002, 59:746-748.

18. Murphy C, Bacon AW, Bondi MW, Salmon DP: Apolipoprotein E status is associated with odor identification deficits in nondemented older persons. Ann N Y Acad Sci 1998, 855:744-750.
19. Bacon AW, Bondi MW, Salmon DP, Murphy C: Very early changes in olfactory functioning due to Alzheimer's disease and the role of apolipoprotein E in olfaction. Ann N Y Acad Sci 1998, 855:723-731.

20. Schiffman SS, Graham BG, Sattely-Miller EA, Zervakis J, Welsh-Bohmer K: Taste, smell and neuropsychological performance of individuals at familial risk for Alzheimer's disease. Neurobiol Aging 2002, 23(3):397-404.

21. Gilbert PE, Murphy C: Differences between recognition memory and remote memory for olfactory and visual stimuli in nondemented elderly individuals genetically at risk for Alzheimer's disease. Exp Gerontol 2004 39(3):433-441.

22. Morgan CD, Nordin S, Murphy C: Odor Identification as an Early Marker for Alzheimers-Disease - Impact of Lexical Functioning and Detection Sensitivity. J Clin Exp Neuropsychol 1995, 17(5):793-803.

23. Olofsson JK, Nordin S, Wiens S, Hedner M, Nilsson LG, Larsson M: Odor identification impairment in carriers of ApoE-varepsilon4 is independent of clinical dementia. Neurobiol Aging 2010, 31(4):567-577.

24. Calhoun-Haney R, Murphy C: Apolipoprotein epsilon 4 is associated with more rapid decline in odor identification than in odor threshold or Dementia Rating Scale scores. Brain Cogn 2005, 58(2):178-182.

25. Murphy C, Jernigan TL, Fennema-Notestine C: Left hippocampal volume loss in Alzheimer's disease is reflected in performance on odor identification: a structural MRI study. J Int Neuropsychol Soc 2003, 9(3):459-471.

26. Wilson RS, Arnold SE, Schneider JA, Boyle PA, Buchman AS, Bennett DA: Olfactory Impairment in Presymptomatic Alzheimer's Disease. Ann N Y Aca Sci 2009, 1170(1):730-735(736).

27. Backman L, Andersson JL, Lyberg L, Winblad B, Nordberg A, Almkvist O: Brain regions associated with episodic retrieval in normal aging and Alzheimer's disease. Neurology 1999, 52(9):1861-1870.

28. Becker JT, Mintun MA, Aleva K, Wiseman MB, Nichols T, DeKosky ST: Compensatory reallocation of brain resources supporting verbal episodic memory in Alzheimer's disease. Neurology 1996, 46(3):692-700

29. Bondi MW, Houston WS, Eyler LT, Brown GG: fMRI evidence of compensatory mechanisms in older adults at genetic risk for Alzheimer disease. Neurology 2005, 64(3):501-508.

30. Bookheimer SY, Strojwas MH, Cohen MS, Saunders AM, Pericak-Vance MA, Mazziotta JC, Small GW: Patterns of brain activation in people at risk for Alzheimer's disease. N Engl J Med 2000, 343(7):450-456.

31. Grady CL, Mclntosh AR, Beig S, Keightley ML, Burian H, Black SE: Evidence from functional neuroimaging of a compensatory prefrontal network in Alzheimer's disease. J Neurosci 2003, 23(3):986-993.

32. Saykin AJ, Flashman LA, Frutiger SA, Johnson SC, Mamourian AC, Moritz CH, O'Jile JR, Riordan HJ, Santulli RB, Smith CA, Weaver JB: Neuroanatomic substrates of semantic memory impairment in Alzheimer's disease: patterns of functional MRI activation. J Int Neuropscyhol Soc 1999, 5(5):377-392.

33. Woodard JL, Grafton ST, Votaw JR, Green RC, Dobraski ME, Hoffman JM: Compensatory recruitment of neural resources during overt rehearsal of word lists in Alzheimer's disease. Neuropsychology 1998, 12(4):491-504.

34. Seidenberg M, Guidotti L, Nielson KA, Woodard JL, Durgerian S, Antuono P, Zhang Q, Rao SM: Semantic memory activation in individuals at risk for developing Alzheimer disease. Neurology 2009, 73(8):612-620.

35. Rombouts SA, Barkhof F, van Meel CS, Scheltens P: Alterations in brain activation during cholinergic enhancement with rivastigmine in Alzheimer's disease. J Neurol Neurosurg Psychiatry 2002, 73(6):665-671.

36. Covington JW, Geisler MW, Polich J, Murphy C: Normal aging and odor intensity effects on the olfactory event-related potential. Int $J$ Psychophysiol 1999, 32(3):205-214

37. Evans WJ, Cui L, Starr A: Olfactory event-related potentials in normal human subjects: effects of age and gender. Electroencephalogr Clin Neurophysiol 1995, 95(4):293-301.

38. Morgan CD, Covington JW, Geisler MW, Polich J, Murphy C: Olfactory event-related potentials: older males demonstrate the greatest deficits. Electroencephalogr Clin Neurophysiol 1997, 104(4):351-358.

39. Morgan CD, Geisler MW, Covington JW, Polich J, Murphy C: Olfactory P3 in young and older adults. Psychophysiology 1999, 36(3):281-287.

40. Morgan CD, Murphy C: Differential effects of active attention and age on event-related potentials to visual and olfactory stimuli. Int J Psychophysiol 2010, 78(2):190-199.

41. Murphy C, Morgan CD, Geisler MW, Wetter S, Covington JW, Madowitz MD, Nordin S, Polich JM: Olfactory event-related potentials and aging: normative data. Int J Psychophysiol 2000, 36(2):133-145. 
42. Nordin S, Quinonez C, Morgan CD, Geisler MW, Polich J, Murphy C: Olfactory event-related potentials in young and elderly adults: evaluation of tracking task versus eyes open/closed recording. Chem Senses 1999, 24(4):459-464.

43. Thesen T, Wetter S, Murphy C: Olfactory event-related potential detects age-related changes in olfactory processing with velopharyngeal closure and normal breathing. Psychophysiology 2000, 37:597.

44. Wetter S, Murphy C: Individuals with Down's syndrome demonstrate abnormal olfactory event-related potentials. Clin Neurophysiol 1999, 110(9):1563-1569.

45. Wetter S, Peavy G, Jacobson M, Hamilton J, Salmon D, Murphy C: Olfactory and auditory event-related potentials in Huntington's disease. Neuropsychology 2005, 19(4):428-436.

46. Kobal G: Elektrophysiologische Untersuchungen des menschlichen Geruchsinns. Stuttgart: Thieme; 1981

47. Lorig TS, Elmes DG, Zald DH, Pardo JV: A computer-controlled olfactometer for fMRI and electrophysiological studies of olfaction. Behav Res Methods Instrum Comput 1999, 31(2):370-375.

48. Lorig TS: The application of electroencephalographic techniques to the study of human olfaction: a review and tutorial. Int J Psychophysiol 2000, 36(2):91-104.

49. Murphy C, Nordin S, de Wijk RA, Cain WS, Polich J: Olfactory-evoked potentials: assessment of young and elderly, and comparison to psychophysical threshold. Chem Senses 1994, 19(1):47-56.

50. Overbosch P, de Wijk R, de Jonge TJ, Koster EP: Temporal integration and reaction times in human smell. Physiol Behav 1989, 45(3):615-626.

51. Ekman GB, Berglund $U$, Berglund B, Lindwall T: Perceived intensity of odor: a function of time of adaptation. Scan J Psychol 1967, 8:177-186.

52. Wilson DA, Linster C: Neurobiology of simple memory. J Neurophysiol 2008, 100:2-7.

53. Polich J: P300, probability, and inter-stimulus interval. Psychophysiology 1990, 27:396-403.

54. Polich J: Probability and inter-stimulus interval effects on the P300 from auditory stimuli. Int J Psychophysiol 1990, 10:163-170.

55. Polich J: P300 in clinical applications: meaning, method, and measurement. In Electroencephalography: Basic Principles, Clinical Applications, and Related Fields. 3rd edition. Edited by Niedermeyer E, Lopes da Silva F. Baltimore, MD: Williams and Wilkins; 1993:1005-1018.

56. Moore PA: A model of the role of adaptation and disadaptation in olfactory receptor neurons: implications for the coding of temporal and intensity patterns in odor signals. Chem Senses 1994, 19(1):17-86.

57. Murphy C, Morgan CD: Olfactory Function and Event-Related Potentials in Alzheimers Disease. In Alzheimer's Disease: Advances in Etiology, Pathogenesis and Therapeutics. Edited by labal K, Sisodia SS, Winblad B. Chichester, UK: John Wiley and Sons, Ltd; 2001:237-251.

58. Donchin E, Heffley E, Hillyard SA, Loveless N, Maltzman I, Ohman A, Rosler F, Ruchkin D, Siddle D: Cognition and event-related potentials. II. The orienting reflex and P300. Ann N Y Acad Sci 1984, 425:39-57.

59. Polich J, Hoffman LD: P300 and handedness: on the possible contribution of corpus callosal size to ERPs. Psychophysiology 1993, 35(5):497-507.

60. Geisler MW, Morgan CD, Covington JW, Murphy C: Neuropsychological performance and cognitive olfactory event-related brain potentials in young and elderly adults. J Clin Exp Neuropsychol 1999, 21(1):108-126.

61. Morgan CD, Murphy C: Olfactory event-related potentials in Alzheimer's disease. J Int Neuropsychol Soc 2002, 8(6):753-763.

62. Wetter S, Murphy C: Apolipoprotein E epsilon 4 positive individuals demonstrate delayed olfactory event-related potentials. Neurobiol Aging 2001, 22(3):439-447.

63. Murphy C, Solomon ES, Haase L, Wang M, Morgan CD: Olfaction in aging and Alzheimer's disease: event-related potentials to a cross-modal odorrecognition memory task discriminate ApoE epsilon4+ and ApoE epsilon 4- individuals. Ann N Y Acad Sci 2009, 1170:647-657.

64. Cain WS, Gent J, Catalanotto FA, Goodspeed RB: Clinical evaluation of olfaction. Am J Otolaryngol 1983, 4(4):252-256

65. Murphy C, Gilmore MM, Seery CS, Salmon DP, Lasker BR: Olfactory thresholds are associated with degree of dementia in Alzheimer's disease. Neurobiol Aging 1990, 11(4):465-469.

66. Mattis S: Mental status examination for organic mental syndrome in the elderly patient. In Geriatric psychiatry: A handbook for psychiatrists and primary care physicians. Edited by Bellak L, Katasu TB. New York: Grune and Statton; 1976:77-121.
67. Sundermann EE, Gilbert PE, Murphy C: Apolipoprotein E epsilon 4 genotype and gender: Effects on memory. Am J Geriatr Psychiatry 2007, 15(10):869-878.

68. Zamora R, Bartholow J, Green E, Morgan CD, Murphy C: Adiposity measures predict olfactory processing speed in older adult carriers of the apolipoprotein E4 allele. Clin Neurophysiol 2011, doi:10.1016/j. clinph.2011.09.001.

69. Murphy C, Schubert CR, Cruickshanks KJ, Klein BE, Klein R, Nondahl DM: Prevalence of olfactory impairment in older adults. JAMA 2002, 288(18):2307-2312.

70. Thesen T, Murphy C: Age-related changes in olfactory processing detected with olfactory event-related brain potentials using velopharyngeal closure and natural breathing. Int J Psychophysiol 2001, 40(2):119-127

71. Kaplan E, Goodglass H, Weintrab S: The Boston Naming Test. Philadelphia: Lea and Febiger; 1983

72. Green J, Levey Al: Event-related potential changes in groups at increased risk for Alzheimer disease. Arch Neurol 1999, 56(11):1398-1403.

73. Olichney JM, Taylor JR, Gatherwright J, Salmon DP, Bressler AJ, Kutas M, IraguiMadoz VJ: Patients with $\mathrm{MCl}$ and $\mathrm{N} 400$ or P600 abnormalities are at very high risk for conversion to dementia. Neurology 2008, 70(19):1763-1770.

74. Chapman RM, Nowlis GH, McCrary JW, Chapman JA, Sandoval TC, Guillily MD, Gardner MN, Reilly LA: Brain event-related potentials: diagnosing early-stage Alzheimer's disease. Neurobiol Aging 2007, 28(2):194-201.

75. Han SD, Houston WS, Jak AJ, Eyler LT, Nagel BJ, Fleisher AS, Brown GG, Cory-Bloom J, Salmon D, Thal LJ, Bondi MW: Verbal paired-associate learning by APOE genotype in non-demented older adults: fMRI evidence of a right hemispheric compensatory response. Neurobiol Aging 2007, 28(2):238-247.

76. Lind J, Persson J, Ingvar M, Larsson A, Cruts M, Van Broeckhoven C, Adolfsson R, Backman L, Nilsson LG, Petersson KM, Nyberg L: Reduced functional brain activity response in cognitively intact apolipoprotein $E$ epsilon 4 carriers. Brain 2006, 129:1240-1248.

doi:10.1186/1744-9081-8-37

Cite this article as: Morgan and Murphy: Individuals at risk for Alzheimer's disease show differential patterns of ERP brain activation during odor identification. Behavioral and Brain Functions 2012 8:37.

\section{Submit your next manuscript to BioMed Central and take full advantage of:}

- Convenient online submission

- Thorough peer review

- No space constraints or color figure charges

- Immediate publication on acceptance

- Inclusion in PubMed, CAS, Scopus and Google Scholar

- Research which is freely available for redistribution 